\title{
Comprehensive evaluation of different scale cities' sustainable development for economy, society, and ecological infrastructure in China
}

\author{
Xiao Sun ${ }^{a}$, Xusheng Liu ${ }^{b}$, Feng Li $^{\text {a, }}{ }^{*}$, Yu Tao ${ }^{a}$, Yingshi Song ${ }^{a}$ \\ a State Key Laboratory of Urban and Regional Ecology, Research Center for Eco-Environmental Sciences, Chinese Academy of Sciences, Shuangqing Road 18, \\ Haidian District, Beijing 100085, China \\ b Chinese Academy of Forest Inventory and Planning, State Forestry Administration, Hepingli East Street 18, Xicheng District, Beijing 100714, China
}

\section{A R T I C L E I N F O}

\section{Article history:}

Received 18 March 2015

Received in revised form 28 August 2015

Accepted 1 September 2015

Available online 9 September 2015

\section{Keywords:}

Urbanization

Sustainable development

Ecological infrastructure

\begin{abstract}
A B S T R A C T
Cities are hybrid socioeconomic-natural ecosystems that represent humanity's densest concentrations of people and their activities. Changes in land use have led to the dramatic reduction of urban wetlands and green space which serve as ecological infrastructure in urban areas, bringing further environmental deterioration. Sustainable development is thus necessary to allow urbanization to continue. Urban sustainable development can be monitored using an indicator system that accounts for both socioeconomic development and the construction of ecological infrastructure. We designed a 22-indicator system capable of meeting this need, and applied it to data from 2000 to 2010 for 277 Chinese cities, including megalopolises, large cities, and small or medium-sized cities. Using the Full Permutation Polygon Synthetic Indicator method, results from 2000 to 2010 showed that indicator values for socioeconomic development, ecological infrastructure construction, and comprehensive sustainability improved at all three city scales. Moreover, the sustainable development level increased with increasing city scale, accompanied by decreasing values of energy consumption per unit of Gross Domestic Product (GDP) during ten years, and decreasing potential to improve comprehensive capacity for sustainable development in the future. We also found that the investment in ecological infrastructure construction accounted for only $1.67 \%$ of GDP through 2010 , and its growth did not effectively control pollutant emissions in China. Additional efforts should be made to achieve greater sustainable environmental management. Overall, Chinese cities still have a long way to go to achieve comprehensive sustainable development; thus it is necessary to implement planning and measures to guide future urbanization and ecological infrastructure construction in China.
\end{abstract}

๑) 2015 Elsevier Ltd. All rights reserved.

\section{Introduction}

Cities are complex hybrid socioeconomic-natural ecosystems, representing the densest concentrations of human activity (Wang et al., 2011). More than half of the world's population now lives in cities (Xu et al., 2012). China's urban population has surged from 17\% of the total in 1978 to 50\% in 2010 (Tian and Qiao, 2014). China's urbanization has recently entered a crucial period (Wei and Ye, 2014). The pace of China's population urbanization, economic

\footnotetext{
* Corresponding author. Tel.: +8610 62849103.

E-mail addresses: sxdreamfree@163.com (X. Sun), liuxush@163.com (X. Liu), lifeng@rcees.ac.cn (F. Li), taoyu880216@126.com (Y. Tao), keystone2006@163.com (Y. Song).
}

urbanization (Zhang et al., 2014), and spatial urbanization (Sun et al., 2013) has been accelerating rapidly. Changes in land use have led to a reduction of 8.3 million hectares in cultivated land and 3.4 million hectares in wetlands during the ten years throughout the whole country. What is more, as the urban wetlands and green space which serve as ecological infrastructure in urban areas provide a wide range of ecosystem services, the changes of their structure and function in the process of urbanization would further lead to decreased species richness (McKenny, 2008), degraded water quality (Seilheimer et al., 2007), increased heat island effect (Liu et al., 2013), and increased air pollution (Xia et al., 2014).

The traditional urbanization model in China has been found to be unsustainable ( $\mathrm{Ni}, 2013)$. The only way out is to pursue the strategy of sustainable development (Zhang and Wen, 2008). China 
should implement an effective strategy of low resource consumption coupled with stable and sustained economic growth. In 1994, China adopted "Agenda 21" (http://www.acca21.org.cn/english/ index.html), in which the government proposed the goal of promoting sustainable and coordinated development of the economy, society, and resources, combined with protection of the environment. Achieving this goal is crucial, as China is now the world's second-largest economy and largest consumer of energy, with proportionally high carbon emissions. Thus, China's urbanization process will have decisive impacts on the national and global environment. The implementation of truly sustainable development in China is crucial, both to sustain the urbanization process (Wang et al., 2013; Ericson, 2006; Jansson, 2013) and to minimize the inevitable regional and international environmental impacts.

Urban sustainable development does not target only one specific aspect. Studies mainly focus on trying to balance the development of economic growth, social progress, ecological construction, and environmental protection (Riley, 2001a). At present, there is still no mature indicator system and evaluation method that can be used for all purposes (Hak et al., 2012). Different indicators and methods have been suggested or used in varied contexts and for diverse purposes (Riley, 2001b). Because of the high level of economic development, technical strength, per capita income, and advanced medical care in developed countries, indicator systems there have mainly focused on how to improve people's quality of life, social welfare, and fairness. For example, Sweden's indicator system focused on economic and resourceutilization efficiency, equity and participation, adaptability, and the value of natural capital and resources for future generations ( $\mathrm{Li}$, 2013).

Developing countries including China, on the other hand, are going through a stage of rapid economic development. There, studies have focused primarily on provinces and municipalities (Yue et al., 2014), on one or a few cities (Li et al., 2009), or on urban communities (Luederitz et al., 2013). Besides, few studies are aimed at hundreds of cities in China (Li et al., 2014b). In these studies, most indicator systems are based on static or dynamic researches and mainly involved economy, society, environment, and other aspects such as management and culture (Fan and Qi, 2010; Chen et al., 2015). The indicators mainly reflect the reality of urban development in the study areas. Their purpose is to satisfy the particular needs and goals of studies and provide a tool for guidance in sustainable policies and communication to the public (Spangenberg et al., 2002). However, most indicator systems still cannot provide comprehensive objective evidence for evaluating urban sustainable development achieved by urban planning and management (Hiremath et al., 2013). Moreover, it is still an open question to find an appropriate evaluation method (Singh et al., 2012), even though various methods have been proposed, including principal component analysis (Cai and Shang, 2009), super slack-based measure model (Li et al., 2013), and efficiency data envelopment analysis model (Wu et al., 2014). However, the evaluation results of these models are greatly influenced by sample size and structure.

Urban ecological infrastructure (UEI) is the foundation of urban sustainable development. It is the key component to promote a healthy urban ecosystem and human environment. It can provide integrative ecological services for urban dwellers and does not add ecological burdens to the external system (Li et al., 2014a). If we implement the UEI approaches properly, then it will help us to comprehensively manage all aspects of water quantity and quality, energy supply and heat dissipation, soil fertility and nutrient usage, minimize runoff, increase reuse and recycling of waste materials (Xu et al., 2012). In this study we undertook a comprehensive evaluation of the sustainability of urban socioeconomic and ecological infrastructure construction using data from 2000 to 2010 for 277 Chinese cities at three size scales. We adopted a comprehensive indicator method called the "full-permutation-polygon synthetic indicator" method (Li et al., 2009). This approach combines a large number of individual indicators into a single sustainability index that allows both static analysis (comparisons within a single year) and dynamic analysis (trends over time). The method offers a combination of simplicity (the data are generally easily available) and comprehensiveness (it accounts for a large range of factors). We used this approach to develop an indicator system for assessing the sustainability of socioeconomic development that is suitable for China's unique characteristics. It can reflect some problems for different scale cities in the process of urbanization and provide a promising basis for decision-making to support urban sustainable development.

\section{Methodology}

\subsection{Study area}

We selected cities that covered a range of size scales to allow a comprehensive evaluation of their capacity for sustainability, and examined the differences among scales and changes in this capacity over time. We focused on cities in mainland China (i.e., excluding Taiwan, Hong Kong, Macao, and Tibet). At present, there is no unified definition for the scales of cities in China. We referred to the China Small and Medium-sized City Development Report (CCDMSC, 2010) in order to analyze and reflect the characteristics and rules of cities' development during the period from 2000 to 2010. We divided the cities at the prefecture level or above into three types: megalopolis (population of more than 3 million), large city (between 1 million and 3 million), and small or medium-sized city (less than 1 million). Our final sample included 20 megalopolises, 105 large cities, and 152 small or medium-sized cities (Fig. 1), which we selected based on the availability of data from 2000 to 2010 . The scope of research only contains the municipal districts.

\subsection{Construction of the indicator system}

In this study, the criteria for developing an urban sustainable development indicator system include the following. First, the indicators should be measurable, comprehensive, and independent from each other (Zhang et al., 2006; Lin and Xia, 2013). Second, the indicators should be able to play a role in improving the management of cities (Button, 2002). Third, the indicator system should be flexible enough to respond to the different needs of urban management at different scales of the urban system (Repetti and Desthieux, 2006). What is more, the indicator system we established was limited by the completeness of the data. If we had chosen too few indicators, then they could not fully explain the problem. However, if we had chosen too many indicators, then they would contain duplicate information (Lin and Xia, 2013). Therefore, we selected representative indicators that were supported by existing data and did not duplicate information.

As the significance of urban sustainable development has been gradually realized, efforts to promote the practice have led to the development of policies and incentives to effectively integrate the concerns on economy development, social progress and ecological infrastructure construction into urban development plans (Holden et al., 2008). On the one hand, urban ecological infrastructure is the basic material condition for social and economic development. It cannot only promote the physical and mental health of residents, but also can stimulate the economic and social development. On the other hand, with the fast growth of economy and population, the cities expand rapidly resulting in further structural and 


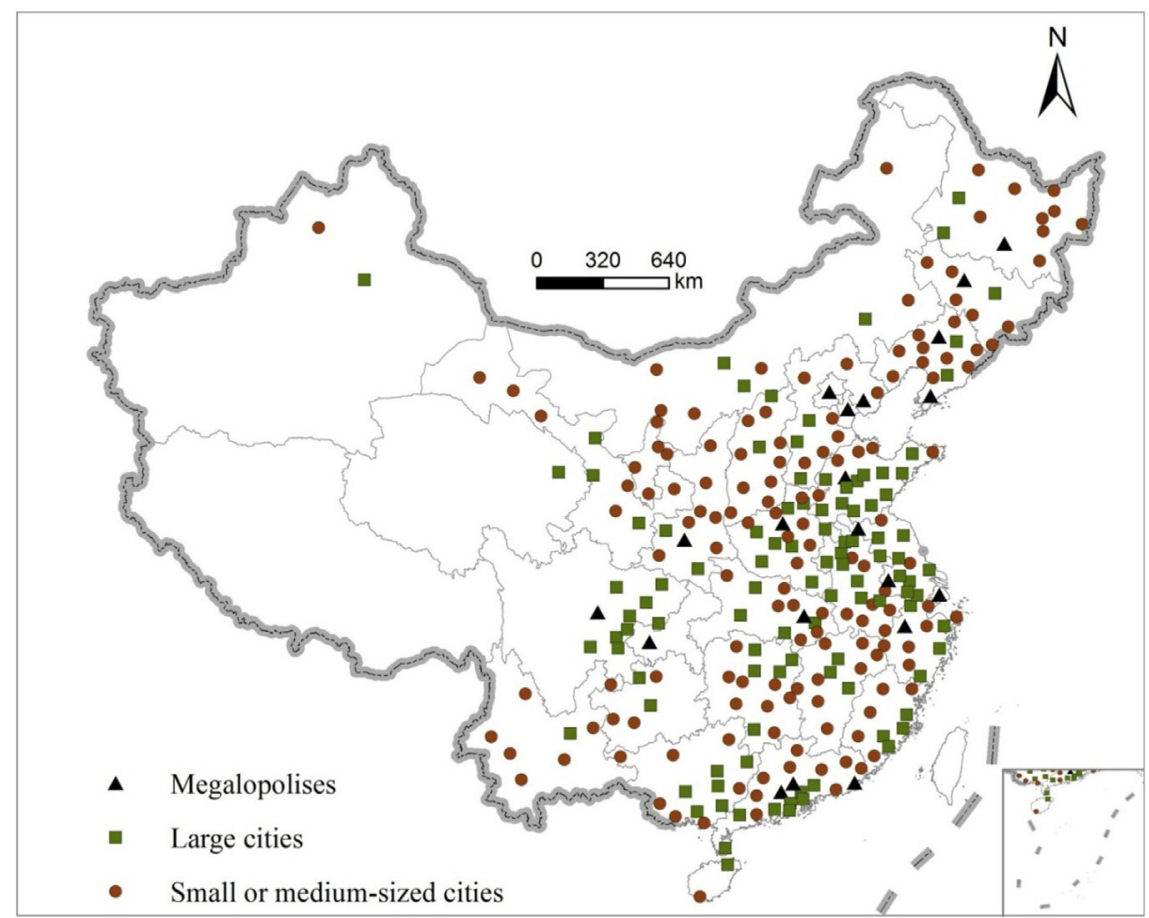

Fig. 1. Spatial distribution of Chinese cities in the present study: 20 megalopolises, 105 large cities, and 152 small or medium-sized cities.

functional changes of ecological infrastructure. This directly influenced urban ecological system and living environment (Scalenghe and Marsan, 2009).

Thus, we designed an indicator system that comprised 22 indicators to evaluate the capacity for sustainability of different scale cities. The indicator system could reflect the socioeconomic development and ecological infrastructure construction of each city (Table 1 ). The indicators for economic development mainly reflect three aspects of urban economy: overall economic strength, living standards of people and industrial structure. The indicators for social progress mainly reflect three aspects of urban society: population quality, public services and living conditions. Finally, the indicators for ecological infrastructure construction mainly include three perspectives of urban ecological infrastructure: the level of greening, land utilization and pollution control.

The data for 2000-2010 were obtained primarily from the China City Statistical Yearbook (NBSC, 2001-2011) and the China Statistical Yearbook on Environment (NBSC and MEPC, 2001-2011). In addition, a few values missing from these two data sources were collected from China's economic and social development statistical database (http://tongji.cnki.net/kns55/). The data for individual cities are comparable because all data were collected and validated using the same protocols.

\subsection{Calculation of an overall sustainability index}

In the "Full Permutation Polygon Synthetic Indicator" method (Li et al., 2009), we used an n-sided polygon to visualize the $n$ indicators, and used the radius at each vertex to represent the standardized value of that indicator. Thus, $(n-2) ! / 2$ n-sided polygons can be formed by $n$ indicators. The synthetic index equaled the mean of the ratio of the area of any n-sided polygon to the area of the polygon defined using a standardized value of 1.0 for each indicator. The standardization process can be described as follows:
$S_{i}=\frac{\left(U_{i}-L_{i}\right)\left(X_{i}-T_{i}\right)}{\left(U_{i}+L_{i}-2 \cdot T_{i}\right) X_{i}+U_{i} \cdot T_{i}+L_{i} \cdot T_{i}-2 \cdot U_{i} L_{i}}$

where $S_{i}$ represents the standardized value for indicator i (with i representing the level 3 indicators in Table 1 ) for each city, and $U, L$, and $T$ represent the corresponding upper limit, lower limit, and threshold (the mean) for the indicator $i$, respectively. represents the value obtained from the database for indicator $\mathrm{i}$.

To visualize the data, a regular $n$-sided polygon can be formed by graphing the values of $n$ indicators, where the vertices represent a value of $S_{i}=1$ and the central point (the origin) represents $S_{i}=-1$. An inner polygon that lies midway between the outer polygon and central point represents the threshold values of the indicators, where $S_{i}=0$ (and thus, $X_{i}=T_{i}$ ). The values of the standardized indicators are less than their thresholds inside the inner polygon and are negative; The values are greater than their threshold values outside the inner polygon and are positive (Fig. 2). The size of each indicator, the gap between its minimum or maximum from the critical value and the changing dynamics can be seen in Fig. 2 .

The value of $S$ can be calculated as follows:

$S=\frac{\sum_{i \neq j}^{i j}\left(S_{i}+1\right)\left(S_{j}+1\right)}{2 \cdot n \cdot(n-1)}$

where $S_{i}$ and $S_{j}$ represent the standardized values for two level 3 indicators which are included in the same level 2 indicator. $S$ represents the synthetic indicator value of level 2 indicator (e.g. the sustainability indicator values for economic development, social progress, and ecological infrastructure construction). Similarly, $S$ can be standardized to account for the immediately higher level in the hierarchy (indicator value for comprehensive capacity for sustainable development) by using this formula.

The synthetic method moved away from the traditional addition of indicators to multidimensional multiplication. The value of the synthetic indicator is minimized as values of the individual 
Table 1

An evaluation indicator system for sustainable development of cities at different scales.

\begin{tabular}{|c|c|c|c|c|c|c|}
\hline Level 1 indicator & Level 2 indicators & Level 3 indicators & Units & $\begin{array}{l}\text { Lower } \\
\text { limit (5\%) }\end{array}$ & $\begin{array}{l}\text { Critical } \\
\text { threshold } \\
\text { (average) }\end{array}$ & $\begin{array}{l}\text { Upper } \\
\text { limit } \\
(95 \%)\end{array}$ \\
\hline \multirow{22}{*}{$\begin{array}{l}\text { Comprehensive } \\
\text { capacity for } \\
\text { sustainable } \\
\text { urban } \\
\text { development }\end{array}$} & Economic & 1 Per capita GDP & RMB & 5322 & 27,769 & 73,891 \\
\hline & \multirow[t]{5}{*}{ development } & 2 Average annual per capita tax revenues & RMB & 189 & 2327 & 7518 \\
\hline & & 3 Per capita investment in fixed assets & RMB & 1459 & 16,570 & 52,697 \\
\hline & & 4 Average annual income per urban resident & RMB & 4438 & 11,679 & 22,917 \\
\hline & & 5 Proportion of secondary industry ${ }^{\mathrm{a}}$ & $\%$ & 28.3 & 50.1 & 70.6 \\
\hline & & 6 Proportion of tertiary industry ${ }^{\mathrm{b}}$ & $\%$ & 25.6 & 41.6 & 59.6 \\
\hline & \multirow[t]{8}{*}{ Social progress } & 7 Proportion of non-agricultural population & $\%$ & 19.3 & 60.9 & 95.5 \\
\hline & & 8 Urban population density & People $/ \mathrm{km}^{2}$ & 131 & 1090 & 2932 \\
\hline & & $\begin{array}{l}9 \text { Number of people who have graduated } \\
\text { from at least technical programs or high school }\end{array}$ & Per $10^{4}$ people & 470 & 744 & 1267 \\
\hline & & $\begin{array}{l}10 \text { Public library collection (number of books } \\
\text { and other items) }\end{array}$ & Items/100 people & 8.9 & 69.3 & 206.2 \\
\hline & & 11 Number of doctors & Per $10^{4}$ people & 10.4 & 27.9 & 50.2 \\
\hline & & 12 Number of public buses and trams & Vehicles $/ 10^{4}$ people & 1.0 & 6.6 & 15.4 \\
\hline & & 13 Per capita area of paved roads & $\mathrm{m}^{2}$ & 2.2 & 8.0 & 17.7 \\
\hline & & 14 Per capita living space & $\mathrm{m}^{2}$ & 8.0 & 21.5 & 46.0 \\
\hline & \multirow{8}{*}{$\begin{array}{l}\text { Ecological } \\
\text { infrastructure } \\
\text { construction }\end{array}$} & 15 Per capita green area & $\mathrm{m}^{2}$ & 5.0 & 31.9 & 75.9 \\
\hline & & 16 Per capita area of ecological land ${ }^{c}$ & $\mathrm{~m}^{2}$ & 2.5 & 24.9 & 75.5 \\
\hline & & 17 Hazard-free treatment rate of urban household waste & $\%$ & 20.0 & 74.7 & 100.0 \\
\hline & & 18 Comprehensive utilization rate of industrial solid wastes & $\%$ & 25.2 & 74.5 & 99.9 \\
\hline & & 19 Standards attainment rate of industrial waste water & $\%$ & 44.7 & 86.4 & 100.0 \\
\hline & & 20 Urban sewage treatment rate & $\%$ & 7.0 & 53.4 & 91.8 \\
\hline & & 21 Removal rate of $\mathrm{SO}_{2}$ & $\%$ & 2.5 & 31.7 & 78.4 \\
\hline & & 22 Removal rate of industrial soot & $\%$ & 46.8 & 88.4 & 99.3 \\
\hline
\end{tabular}

a Secondary industry refers to all industries that process raw materials into manufactured products, and the construction industry.

b Tertiary industry in Table 1 means service industry.

c The area of ecological land represents the area of a municipal district minus the built-up area in the municipal district.

indicators fall below the thresholds, while the synthetic indicator value is magnified as the values rise above the thresholds. This reflects the integrative systems principle that the whole can be more than or less than the sum of its parts. The sensitivity of results is thereby improved, and the upper and lower values of each indicator can be easily identified. As a result, the method is more rational and objective, while still permitting a detailed analysis.

In this study, the analysis began by ranking the cities in descending order based on the values of their indicators in 2000 , 2005 , and 2010. We then calculated the values at the boundaries of the upper 5th percentile and lower 5th percentile, using these as the upper and lower limits, respectively. The mean value represented a critical threshold which separated the relatively sustainable cities from the relatively non-sustainable cities. It is reasonable to use the mean rather than the median as the critical threshold, according to the characteristics of the distribution of each indicator

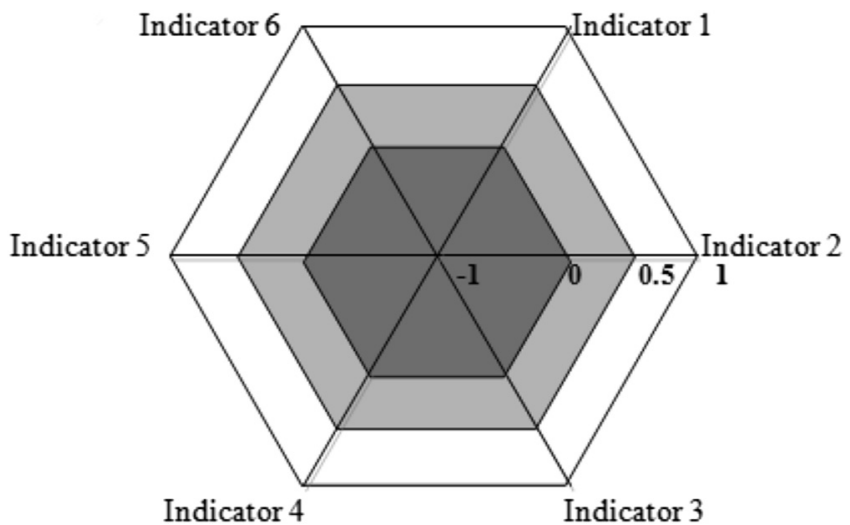

Fig. 2. Illustration of how index values can be visualized using the full permutation polygon. value in this study. This approach ensures that the data on both sides of the critical value are distributed uniformly. We set the standardized values for cities in the upper and lower 5th percentile as 1 and -1 , respectively. This eliminated the problematic impact of maximum and minimum values of the indicator on data standardization. If the standardized value of the indicator for a city was positive, this indicated that the city had a better-than-average value for that indicator; conversely, negative values represented a worsethan-average value.

Previously developed methods (Pohekar and Ramachandran, 2004) apply weights to the various indicators to account for their relative importance, but these methods have the problem of subjectivity in the process of determining the indicator weights. To avoid this problem, we assigned equal weights to the indicators because cities at each scale have their own specific indicator characteristics, making it impossible to assign a single set of standard weights that would be relevant at all scales. Future research should determine whether it is possible to obtain an objective weighting of the parameters that applies at all three scales, or whether it is appropriate to use different weights at different scales.

We defined specific $S$ values for each of the 24 indicators, combining them into a composite value for the economic, social, and ecological infrastructure sustainability indices, and a composite value that combines all three. In order to provide a qualitative interpretation of the meaning of the indicator values, we adopted a four-level classification scheme (Li et al., 2009) based on the values of the sustainability index (Table 2).

\section{Results}

\subsection{Changes in the indicator values from 2000 to 2010}

Changes from 2000 to 2010 in the specific indicators for economic development, social progress, and ecological infrastructure construction for cities at the three scales are presented in Fig. 3. 
Table 2

Classification scheme for the sustainability capacity (S).

\begin{tabular}{lll}
\hline Level & Value of $S$ & Qualitative evaluation \\
\hline I & $S \geq 0.75$ & Excellent \\
II & $0.5 \leq S<0.75$ & Good \\
III & $0.25 \leq S<0.5$ & Moderate \\
IV & $S<0.25$ & Poor \\
\hline
\end{tabular}

\subsubsection{Megalopolises}

For the economic development indicators, the indicator value for the proportion of secondary industry increased slightly and the indicator value for the proportion of tertiary industry decreased slightly from 2000 to 2010 . The other indicators increased greatly from 2000 to 2010. This illustrates that the overall level of economic development of the megalopolises increased rapidly, but that changes in the industrial structure were not the dominant factor.

For the social progress indicators, the large number of agricultural workers who moved into megalopolises led to a slight decrease in the proportion of the non-agricultural population. In addition, urban population density decreased slightly. This was due to high housing prices and poor air quality in the downtown area, along with the improvement of infrastructure in satellite towns, stimulating a population shift from downtown to the surrounding suburbs. Although medical services in megalopolises were the best in the country, per capita medical resources remained low and the number of doctors per 10,000 people decreased slightly from 2000 to 2010. Despite this decline, other social indicators for megalopolises improved during the decade.

For the ecological infrastructure construction indicators, the values for per capita ecological land increased slightly. This is
Megalopolis

Large cities

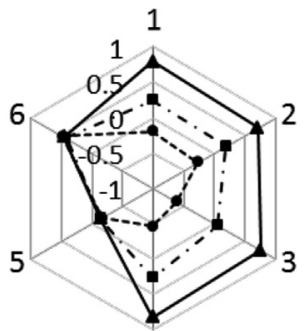

4

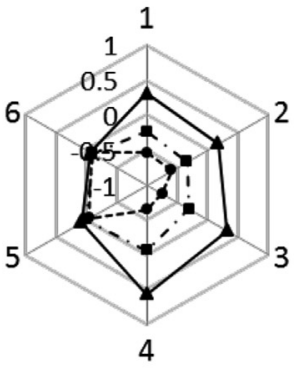

Small or

medium-sized

cities

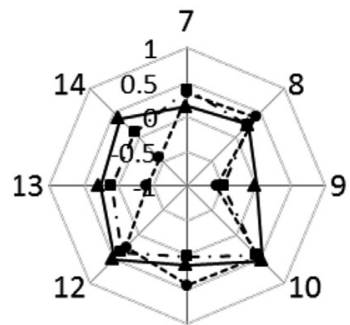

11

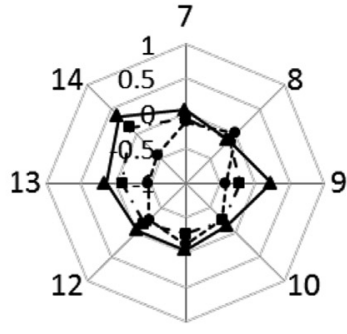

11

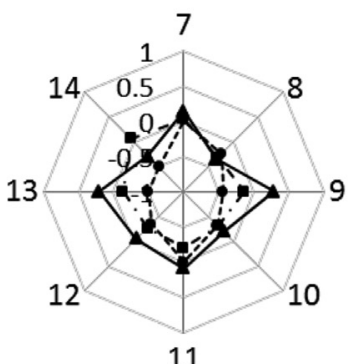

11

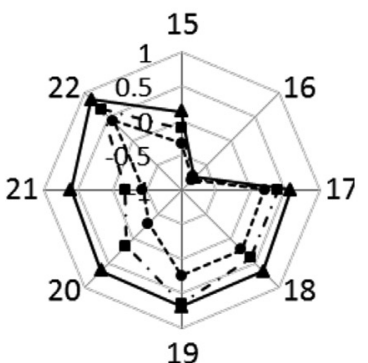

15

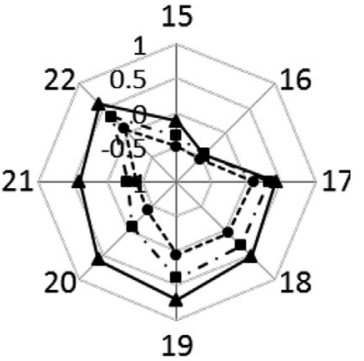

15

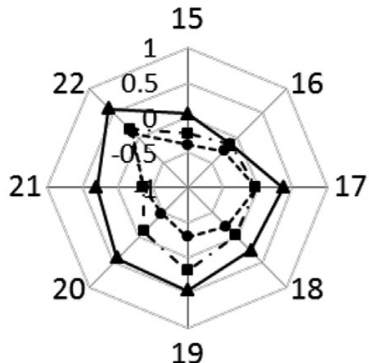

---- $2000 \quad-\cdot 2005 \quad 2010$

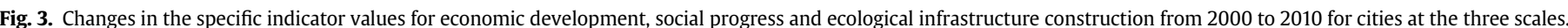

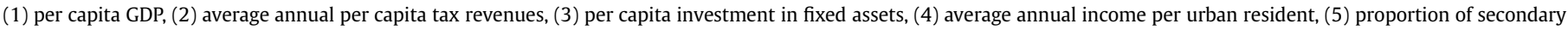

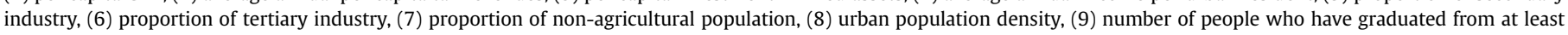

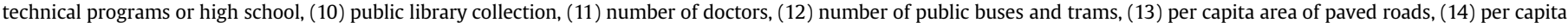

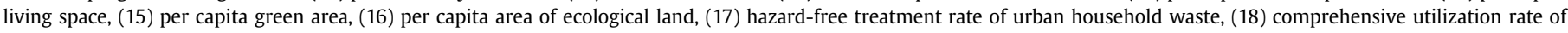

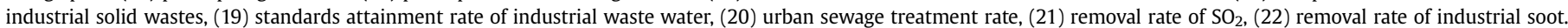


because along with the increase of built-up areas, the total land areas of municipal districts were also expanding at the same time. The municipal districts negatively impacted ecological land (e.g., farmlands, forests, rivers, wetlands, etc.) in the surrounding suburbs during the process of urbanization. Thus, although the values for per capita ecological land slightly increased from 2000 to 2010, this approach to land use was not sustainable. However, other indicators increased greatly, illustrating that the megalopolises strengthened their ecological infrastructure construction over the past decade.

Fig. 4a summarizes trends for comprehensive sustainability indices for economic development, social progress, ecological infrastructure construction, and overall composite sustainable development from 2000 to 2010 . In this paper, we use the mean values to represent the level 1 and level 2 indicator values for different scale cities. The sustainability indicator value for economic development had the greatest increase during ten years. It increased by $236 \%$, representing a change from poor to good. The increase in the sustainability indicator value for social progress was $47 \%$, representing no change in the rating (i.e., the rating remained moderate). The sustainability indicator value for ecological infrastructure construction increased by $146 \%$, moving from the poor to good category. At the same time, the indicator value reflecting comprehensive capacity for sustainable development increased by $123 \%$, from moderate to good.

\subsubsection{Large cities}

For the economic development indicators, the indicator values for the proportions of secondary and tertiary industries increased slightly from 2000 to 2010 in the large cities. The other indicators all increased greatly, leading to a large overall increase in the level of economic development of large cities. The living standards of residents also improved greatly. However, the industrial structure saw almost no change during the ten-year period.

For the social progress indicators, decreasing population growth combined with the expansion of urban construction land to slightly decrease the urban population density. The other indicators all increased from 2000 to 2010. This indicates that public services improved significantly in the large cities.

For the ecological infrastructure construction indicators, all the values increased. In addition to the slight increases for per capita ecological land, other indicator values had large increases.

Fig. 4b shows that from 2000 to 2010, the sustainability indicator values for economic development, social progress, and ecological infrastructure construction all moved from the poor to moderate category, showing increases of 256,89 , and $171 \%$ for large cities. The value of the indicator reflecting comprehensive capacity for sustainable development increased by $155 \%$, but remained in the moderate category despite this increase.

\subsubsection{Small or medium-sized cities}

For the economic development indicators, the indicator values for the proportions of secondary and tertiary industries increased slightly from 2000 to 2010 . The other indicator values all increased greatly. This suggests that the patterns of overall economic development and of specific indicators for small or medium-sized cities were similar to those for large cities.

For the social progress indicators, the indicator value for proportion of non-agricultural population, number of people who have graduated from at least technical programs or high school, public library collection, number of public buses and trams, and per capita area of paved roads all increased gradually from 2000 to 2010 . The indicator value for urban population density decreased slightly. The indicator value for number of doctors decreased from 2000 to 2005, and then increased from 2005 to 2010. This suggests that the

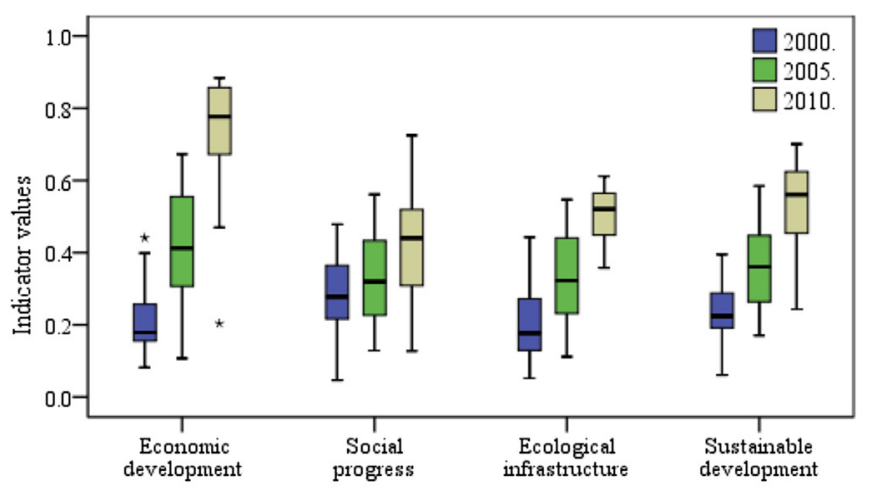

a) Megalopolis

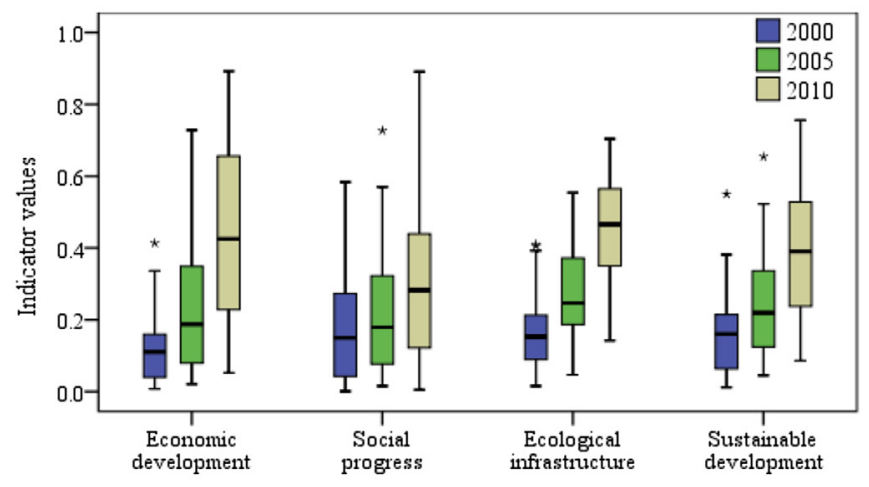

b) Large cities

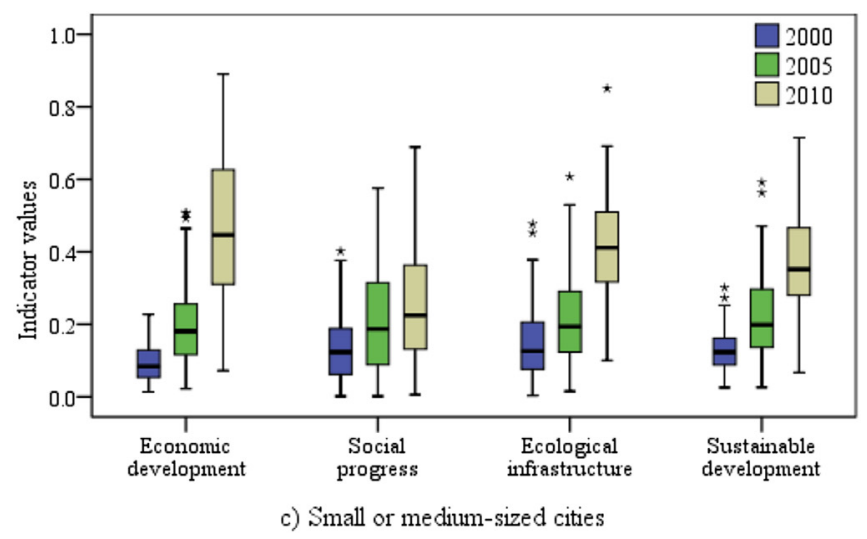

Fig. 4. Evaluation of the sustainability indicators for economic development, social progress and ecological infrastructure construction, and overall composite sustainable development, from 2000 to 2010 , for cities at the three scales.

condition of medical services for small or medium-sized cities has improved as a whole over the past decade. From 2000 to 2005, the population growth rate slowed due to the implementation of family planning, and the per capita housing area increased. Thereafter, the population growth rate increased slightly because China implemented the family planning policy more flexibly, and the per capita housing area decreased with the increasing population.

For the ecological infrastructure construction indicators, the patterns of indicator values for small or medium-sized cities were similar to those for megalopolises and large cities. Most indicator values had large increases, except for the slight increase of indicator values for per capita ecological land.

Fig. 4c shows that from 2000 to 2010 , the sustainability indicator values for economic development, social progress, and 
ecological infrastructure construction of small or medium-sized cities all moved from the poor to moderate category, reflecting increases of $362,91,185$, and $182 \%$, respectively.

\subsection{Variations in the indicator values among different city scales}

The values of the specific indicators that comprise economic development, social progress, and ecological infrastructure construction were different for cities at the three scales, as shown in Fig. 5. These indicator values were obtained by calculating the average value (from 2000 to 2010) for each type of indicator.

\subsubsection{Economic development}

The results show that the indicator values for per capita GDP, average annual per capita tax revenues, per capita investment in fixed assets, and average annual income per urban resident increased with increasing city scale. The sustainability indicator values for economic development decreased from 0.46 (moderate) for megalopolises to 0.29 for large cities and 0.17 for small or medium-sized cities, both of which were ranked as poor (Fig. 6). The level of economic development of megalopolises was much higher than for other types of cities. That is because the larger scale of these cities made possible more policy advantages, economic resources, advanced technology, and better-developed traffic systems during the process of urbanization. However, the indicator value for proportion of secondary industries decreased with increasing city scale. For the indicator values for proportion of tertiary industries, small and medium-sized cities and large cities were almost same, while megalopolises had higher values. This illustrates that in the smaller cities, the industrial sector accounted for a greater proportion of the economic development, and the service industry was less mature.

\subsubsection{Social progress}

For the social characteristics, urban population density increased with increasing city scale. For small and medium-sized cities and large cities, the indicator values for proportion of nonagricultural population, public library collection (number of books and other items), number of doctors, and number of public buses and trams were approximately equal, but less than for megalopolises. The indicator values for per capita living space for megalopolises and large cities were almost same, and were higher than for small and medium-sized cities. Although housing prices in megalopolises and large cities were high, the per capita living space was larger because of the higher degree of housing investment. Due to unified standards in urban road planning, the per capita area of paved roads was almost the same for cities at all three scales. In general, the small and medium-sized cities' level of public welfare

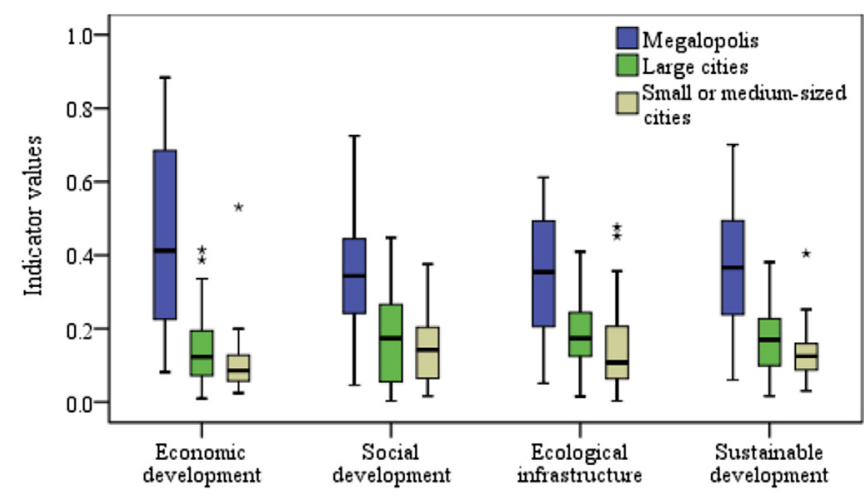

Fig. 6. Comparison of sustainability indicator values for economic development, social progress, and ecological infrastructure construction, and overall composite sustainable development for cities at three size scales.

was lower than that of other types of cities. The sustainability indicator value for social progress decreased from 0.34 for megalopolises (moderate) to 0.23 for large cities and 0.20 for small or medium-sized cities (both ranked as poor) (Fig. 6).

\subsubsection{Ecological infrastructure construction}

For ecological infrastructure construction, with increasing city scale, the indicator values increased for hazard-free treatment rate of urban household waste, comprehensive utilization rate of industrial solid wastes, standards attainment rate of industrial waste water, urban sewage treatment rate, removal rate of $\mathrm{SO}_{2}$, and removal rate of industrial soot. This is because the larger cities could purchase more advanced pollution control techniques and equipment and provide sufficient financial support. The sustainability indicator values for ecological infrastructure construction increased from 0.26 for small or medium-sized cities to 0.29 for large cities and 0.38 for megalopolises (Fig. 6). These values were all ranked as moderate. However, the indicator value for per capita green area of large cities was less than that of other types of cities. The indicator value for per capita area of ecological land decreased with increasing city scale. This indicates that the larger cities pay less attention to the construction of green ecological infrastructure.

\subsubsection{Comprehensive capacity for sustainable urban development}

From 2000 to 2010, the indicator value for comprehensive capacity for sustainable development increased with increasing city scale (Fig. 6). In 2010, for $60 \%$ of the megalopolises, the indicator values for comprehensive capacity for sustainable development were greater than 0.5 , and were thus ranked as good. At 0.70 , Guangzhou was the highest, due to an efficient and coordinated

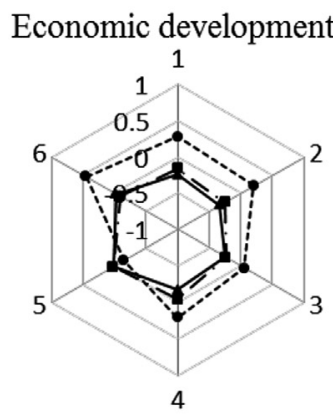

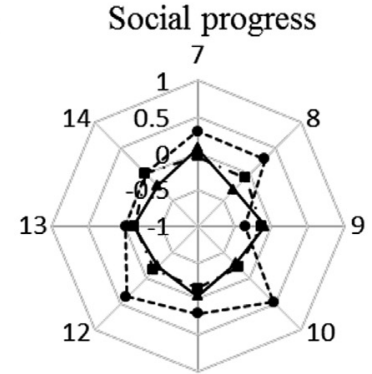

11

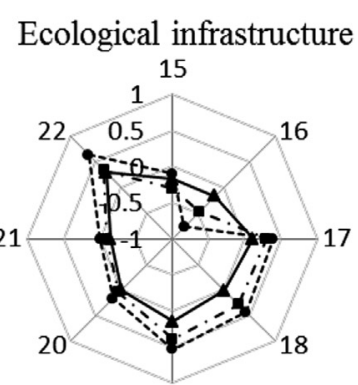

19

--.-- Megalopolis -. - - Large cities $\longleftarrow$ Small or medium-sized cities

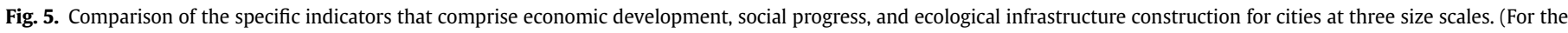
meanings of indicator numbers, see Fig. 3). 
development in economic, social and environmental areas. Wuhan and Dalian ranked second and third, respectively. This is because Wuhan had a well-developed economy and public services provisions, while Dalian had high levels of economic development and ecological infrastructure construction. The indicator values for comprehensive capacity for sustainable development of Chongqing, Xuzhou and Shantou were lower. In particular, the value for Shantou was only 0.24 , which was ranked as poor.

For $32 \%$ of large cities, the indicator values for comprehensive sustainable development were ranked as good in 2010. Among these, the values were greater than 0.70 in Shenzhen, Shijiazhuang, Fuzhou, Qingdao, Xiamen and Wuxi, which was higher than for any of the megalopolises. The explanation for Shijiazhuang was that the level of social progress was high, while the other four cities, located along China's east coast, achieved rapid and coordinated development across all aspects due to their superior geographical location and convenient transportation. Meanwhile, for another 29\% of large cities, the indicator values for comprehensive sustainable development were still ranked as poor in 2010. These cities were mainly distributed in inland provinces like Sichuan, Guangxi and Anhui. They cannot keep up with the pace of urbanization due to the poor transportation and information conditions.

In 2010, the indicator values for comprehensive sustainable development were ranked as good for $14 \%$ of small or mediumsized cities. Ordos was the highest, reaching 0.71 , due to an abundance of rich natural resources and high level of economic development. However, for $30 \%$ of small or medium-sized cities, the indicator values for comprehensive sustainable development were still ranked as poor. These cities were mainly distributed in inland provinces such as Gansu, Ningxia, Yunnan, and parts of the old northeast industrial base.

\section{Discussion}

For cities of different sizes, the overall level of economic development improved significantly from 2000 to 2010. Energy consumption per unit of GDP was decreased by $42 \%$ for megalopolises, $36 \%$ for large cities, and 39\% for small or medium-sized cities during those ten years. The level of economic development increased with increasing city scale, while the values of energy consumption per unit of GDP decreased with increasing city scale. This suggests that the smaller cities contained a smaller proportion of tertiary industry and used a smaller proportion of natural gas and other clean energy. However, the industrial structures of the cities at all three scales showed only minor changes from 2000 to 2010.

Chinese urbanization depends strongly on natural resource inputs (Bai et al., 2012), and the efficiency of energy utilization is still low (Niu et al., 2011). Until now, the theme of green economy, strong sustainable consumption (Lorek and Spangenberg, 2014), and ecological industry has been put forward. When industries are greener (Jung et al., 2013), they minimize unsustainable exploitation of resources and irreversible harm to the environment in their design (Khalili and Duecker, 2013). Thus it is necessary for cities especially small or medium-sized cities - to adjust their economic and industrial structure, reduce the proportion of high consumption and heavy pollution industries, promote the development of green and low-carbon industries (Liu et al., 2014), and build a more sustainable economy (Zhao, 2011).

Overall social progress improved greatly in cities at all three scales from 2000 to 2010 . The larger the scale of cities, the higher the level of basic public services they were able to provide. However, the level of social progress did not keep up with the pace of economic development and ecological infrastructure construction from 2000 to 2010. According to the report of World Bank, in 2010, the expenditure of public health and education on total government expenditure in China is in lower level compared with other countries (Yang et al., 2014). Therefore, different scale cities should increase investment in public services and share the public resources equally (Frie et al., 2010). Government and enterprise should gradually enhance educational and medical services, expand employment channels, and improve the social management system (i.e., carry out measures to guarantee that all urban residents can enjoy similar levels of access to all social services).

The overall ecological infrastructure construction level improved greatly for cities at all three scales from 2000 to 2010. At the same time, China had a 5-fold improvement in investment in ecological infrastructure construction. However, the pollutant emissions still showed an upward tendency (Jie et al., 2010). The investment did not effectively control pollutant emissions in China, although its growth rate was 1.5 times of GDP growth rate. International organizations and economists have concluded that when a country's ecological infrastructure construction investment accounts for $1 \%-2 \%$ of its GDP, the environmental pollution would in principle be under control, and when the investment accounts for $3 \%-5 \%$ of the country's GDP, the environmental quality should improve notably (Bruyn, 2000). In China, the ecological infrastructure construction investment, which includes both governmental budgets and investments by non-governmental investors, accounted for $1.15 \%$ of GDP in 2000 and $1.67 \%$ of GDP in 2010 . This level of investment could presumably control environmental pollution in general, but the overall investment level was lower than that of developed countries. This reveals that the management of China's ecological infrastructure construction still has some serious deficiencies. This is due to an inadequate ecological infrastructure investment structure, lack of effective competition, underdeveloped technology, and inefficient operation of environmental protection facilities. The ineffective supervision of governmental departments also has led to the misuse of investments. In addition, the phenomena of no strict observation of laws, little punishment to law breakers, poor law enforcement and supervision are still very common (Zhang et al., 2013).

Therefore, China's urban ecological infrastructure construction needs to be driven by market forces, not only by governments. For example, the pollution rights trading in the market is an effective way to control environmental pollution. We should first increase the amount of ecological infrastructure construction investment and its ratio to GDP in China. This approach can promote the upgrading of environmental technology and decrease pollution emissions (Lin et al., 2012). To improve the operational efficiency of ecological infrastructure investments, we should establish effective supervision and management mechanisms. The supervision and guarantee system mainly includes automatic online monitoring system, public participation system, etc. Besides, the management mechanism can be implemented by target supervision system, regular reporting system of pollution control, etc. These measures can help to ensure the smooth operation of ecological infrastructure construction. Moreover, promoting the rule of law, optimizing fiscal policy and adjusting the ecological infrastructure investment structure are also effective measures (Aguado et al., 2013). The proportion of investments on industrial pollution source control and high-polluting industries should be raised to improve the investment efficiency.

In terms of comprehensive capacity for sustainable development, the results of this study showed that small or medium-sized cities experienced the greatest increases in certain aspects of economic development, social progress, ecological infrastructure construction, and in their overall sustainability index. The smaller the scale of the city, the more potential there is to improve comprehensive capacity for sustainable development. China should 
focus now on promoting the development of small and mediumsized cities. In addition, different scale cities should further carry out reasonable and phased planning as well as rational development. Attaining sustainable development requires simultaneous balanced development in economic, social, and ecological infrastructure's areas. In this way, we can establish a new urbanization model that will lead us closer to sustainable development.

\section{Acknowledgments}

This research was funded by the National Natural Science Foundation of China (No. 71273254). The authors thank Deborah Rogers, a native English speaker with more than 15 years of experience as a scientific writer and editor, for her constructive suggestions for correcting and polishing the manuscript.

\section{References}

Aguado, S., Alvarez, R., Domingo, R., 2013. Model of efficient and sustainable improvements in a lean production system through processes of environmental innovation. J. Clean. Prod. 47, 141-148.

Bai, Y.P., Niu, J.P., Hao, Y.P., 2012. Research of regional energy efficiency based on undesirable outputs and its influential factors: a case of western China. Energy Procedia 16, 802-809.

Bruyn, S.M., 2000. Economic Growth and the Environment. Springer Netherlands, Kluwer Academic Publishers.

Button, K., 2002. City management and urban environmental indicators. Ecol. Econ. $40,217-233$

Cai, C.M., Shang, J.C., 2009. Comprehensive evaluation on urban sustainable development of Harbin City in Northeast China. Chin. Geogra. Sci. 19 (2), $144-150$.

Chen, X.H., Liu, X., Hu, D.B., 2015. Assessment of sustainable development: a case study of Wuhan as a pilot city in China. Ecol. Indic. 50, 206-214.

China Committee for Development of Medium and Small Cities (CCDMSC), 2010 China Small and Medium-Sized City Development Report (2010): the Development Path of Chinese Small and Medium-sized City. Social Science Academic Press, Beijing (in Chinese).

Ericson, J.A., 2006. A participatory approach to conservation in the Calakmul Biosphere Reserve, Campeche, Mexico. Landsc. Urban Plan. 74, 242-266.

Fan, P.L., Qi, J.G., 2010. Assessing the sustainability of major cities in China. Sustain. Sci. 5 (1), 51-68.

Frie, K.G., Eikemo, T.A., Knesebeck, O., 2010. Education and self-reported health care seeking behavior in European welfare regimes: results from the European Social Survey. Int. J. Public Health 55 (3), 217-220.

Hak, T., Kovanda, J., Weinzettal, J., 2012. A method to assess the relevance of sustainability indicators: application to the indicator set of the Czech Republic's sustainable development strategy. Ecol. Indic. 17, 46-57.

Hiremath, R.B., Balachandra, P., Kumar, B., Bansode, S.S., Murali, J., 2013. Indicatorbased urban sustainability - a review. Energy Sustain. Dev. 17 (6), 555-563.

Holden, M., Roseland, M., Ferguson, K., Perl, A., 2008. Seeking urban sustainability on the world stage. Habitat Int. 32 (3), 305-317.

Jansson, Å., 2013. Reaching for a sustainable, resilient urban future using the lens of ecosystem services. Ecol. Econ. 86, 285-291.

Jie, M.H., Liu, X.W., Bai, M.D., 2010. Empirical analysis of the efficiency of environmental protection investment and policy recommendations. Chin. Popul. Resour. Environ. 20 (4), 100-105 (in Chinese).

Jung, S., Dodbiba, G., Chae, S.H., Fujita, T., 2013. A novel approach for evaluating the performance of eco-industrial park pilot projects. J. Clean. Prod. 39, 50-59.

Khalili, N.R., Duecker, S., 2013. Application of multi-criteria decision analysis in design of sustainable environmental management system framework. J. Clean. Prod. 47, 188-198.

Li, F., Liu, X.S., Hu, D., 2009. Measurement indicators and an evaluation approach for assessing urban sustainable development: a case study for China's Jining City. Landsc. Urban Plan. 90, 134-142.

Li, F., Wang, R.S., Huisingh, D., 2014a. Call for papers for a special volume of the Journal of Cleaner Production on urban ecological infrastructure for healthie cities: governance, management and engineering. J. Clean. Prod. 83 (15), 1-4.

Li, H., Fang, K., Yang, W., Wang, D., Hong, X., 2013. Regional environmental efficiency evaluation in China: analysis based on the Super-SBM model with undesirable outputs. Math. Comput. Model. 58 (5), 1018-1031.

Li, T.X., 2013. Research progress in sustainable development indicator systems both at home and abroad. Ecol. Environ. Sci. 22 (6), 1085-1092 (in Chinese).

Li, X.P., Li, X.J., Woetzel, J., Zhang, G.T., Zhang, Y.J., 2014b. The China Urban Sustainability Index 2013. The Urban China Initiative.

Lin, Z.M., Xia, B., 2013. Sustainability analysis of the urban ecosystem in Guangzhou City based on information entropy between 2004 and 2010. J. Geogr. Sci. 23 (3), $417-435$
Lin, Q.H., Chen, G.Y., Du, W.C., Niu, H.P., 2012. Spillover effect of environmental investment: evidence from panel data at provincial level in China. Front. Environ. Sci. Eng. 6 (3), 412-420.

Liu, L.Q., Liu, C.X., Gao, Y.G., 2014. Green and sustainable city will become the development objective of China's low carbon city in future. J. Environ. Sci China $12(34), 1-10$.

Liu, S.W., Zhang, P.Y., Jiang, X.L., Lo, K., 2013. Measuring sustainable urbanization in China: a case study of the coastal Liaoning area. Sustain. Sci. 8 (4), 585-594.

Lorek, S., Spangenberg, J.H., 2014. Sustainable consumption within a sustainable economy - beyond green growth and green economies. J. Clean. Prod. 63, $33-44$.

Luederitz, C., Lang, D.J., Von Wehrden, H., 2013. A systematic review of guiding principles for sustainable urban neighborhood development. Landsc. Urban Plan. 118, 40-52.

McKenny, M.L., 2008. Effects of urbanization on species richness: a review of plants and animals. Urban Ecosyst. 11 (2), 161-176.

National Bureau of Statistics of China (NBSC), 2001-2011. China City Statistical Yearbook 2001-2011. China Statistical Publication House, Beijing (in Chinese).

National Bureau of Statistics of China (NBSC), Ministry of Environmental Protection of China (MEPC), 2001-2011. China Statistical Yearbook on Environment 20012011. China Statistical Publication House, Beijing (in Chinese).

Ni, P.F., 2013. The goal, path, and policy responses of China's new urbanization. Chin. Fin. Econ. Rev. 1 (2), 1-15.

Niu, S., Ding, Y., Niu, Y., Li, Y., Luo, G., 2011. Economic growth, energy conservation and emissions reduction: a comparative analysis based on panel data for 8 Asian-Pacific countries. Energy Policy 39 (4), 2121-2131.

Pohekar, S.D., Ramachandran, M., 2004. Application of multi-criteria decision making to sustainable energy planning - a review. Renew. Sust. Energy Rev. 8 (4), 365-381.

Repetti, A., Desthieux, G., 2006. A relational indicator set model for urban land-use planning and management: methodological approach and application in two case studies. Landsc. Urban Plan. 77, 196-215.

Riley, J., 2001a. Indicator quality for assessment of impact of multidisciplinary systems. Agric. Ecosyst. Environ. 87, 121-128.

Riley, J., 2001b. The indicator explosion: local needs and international challenges. Agric. Ecosyst. Environ. 87, 119-120.

Scalenghe, R., Marsan, F.A., 2009. The anthropogenic sealing of soils in urban areas. Landsc. Urban Plan. 90 (1), 1-10.

Seilheimer, T.S., Wei, A.H., Chow-Fraser, P., Eyles, N., 2007. Impact of urbanization on the water quality, fish habitat, and fish community of a Lake Ontario marsh, Frenchman's Bay. Urban Ecosyst. 10 (3), 299-319.

Singh, R.K., Murty, H.R., Gupta, S.K., Dikshit, A.K., 2012. An overview of sustainability assessment methodologies. Ecol. Indic. 15 (1), 281-299.

Spangenberg, J.H., Pfahl, S., Deller, K., 2002. Towards indicators for institutional sustainability: lessons from an analysis of Agenda 21. Ecol. Indic. 2, 61-77.

Sun, P.J., Song, W., Xiu, C.L., Liang, Z.M., 2013. Non-coordination in China's urbanization: assessment and affecting factors. Chin. Geogra. Sci. 23 (6), 729-739.

Tian, G.J., Qiao, Z.A., 2014. Assessing the impact of the urbanization process on net primary productivity in China in 1989-2000. Environ. Pollut. 184, 320-326.

Wang, Y.H., Deng, X.M., Marcucci, D.J., Le, Y., 2013. Sustainable development planning of protected areas near cities: case study in China. J. Urban Plan. Dev. 139 (2), 133-143.

Wang, R.S., Li, F., Hu, D., Li, B.L., 2011. Understanding eco-complexity: social-economic-natural complex ecosystem approach. Ecol. Complex 8 (1), 15-29.

Wei, Y.D., Ye, X., 2014. Urbanization, land use, and sustainable development in China. Stoch. Environ. Res. Risk Assess. 28 (4), 755.

Wu, H.Q., Shi, Y., Xia, Q., Zhu, W.D., 2014. Effectiveness of the policy of circular economy in China: a DEA-based analysis for the period of 11th five-year-plan. Resour. Conserv. Recycl 83, 163-175.

Xia, T.Y., Wang, J.Y., Song, K., Da, L.J., 2014. Variations in air quality during rapid urbanization in Shanghai. China. Landsc. Ecol. Eng. 10 (1), 181-190.

Xu, M., Weissburg, M., Newell, J.P., Crittenden, J.C., 2012. Developing a science of infrastructure ecology for sustainable urban systems. Environ. Sci. Technol. 46 (15), 7928-7929.

Yang, Z., Yi, C.D., Zhang, W., Zhang, C., 2014. Affordability of housing and accessibility of public services: evaluation of housing programs in Beijing. J. Hous. Built Environ. 29 (3), 521-540.

Yue, W.Z., Fan, P.L., Wei, Y.H., Qi, J.G., 2014. Economic development, urban expansion, and sustainable development in Shanghai. Stoch. Environ. Res. Risk Assess. 28 (4), 783-799.

Zhang, K.M., Wen, G.Z., 2008. Review and challenges of policies of environmental protection and sustainable development in China. J. Environ. Manage. 88 (4), 1249-1261.

Zhang, X.H., Wu, L.Q., Zhang, R., Deng, S.H., Zhang, Y.Z., Wu, Jun, Li, Y.W., Lin, L.L., Li, L., Wang, Y.J., Wang, L.L., 2013. Evaluating the relationships among economic growth, energy consumption, air emissions and air environmental protection investment in China. Renew. Sust. Energy Rev. 18, 259-270.

Zhang, Y., Yang, Z.F., Yu, X.Y., 2006. Measurement and evaluation of interactions in complex urban ecosystem. Ecol. Model. 196 (1-2), 77-89.

Zhang, Y.J., Zhao, L., Zhang, H., Tan, T.D., 2014. The impact of economic growth, industrial structure and urbanization on carbon emission intensity in China. Nat. Hazards 73 (2), 579-595.

Zhao, J.Z., 2011. Towards Sustainable Cities in China: Analysis and Assessment of Some Chinese Cities in 2008. Springer, New York. 